\title{
Urban Heat Island Characterization and Isotherm Mapping Using Geo-Informatics Technology in Ahmedabad City, Gujarat State, India
}

\author{
Ram Joshi', Hardik Raval1, Maharshi Pathak', Sumit Prajapati², Ajay Patel2, Vijay Singh², \\ Manik H. Kalubarme ${ }^{2}$ \\ ${ }^{1}$ Department of Civil Engineering, School of Technology, Pandit Deendayal Petroleum University, Gandhinagar, \\ India \\ ${ }^{2}$ Bhaskaracharya Institute for Space Applications and Geo-Informatics (BISAG), Department of Science \& \\ Technology, Government of Gujarat, Gandhinagar, India \\ Email: ramjoshi1992@gmail.com, ${ }^{*}$ mhkalubarme@gmail.com
}

Received 28 February 2015; accepted 22 March 2015; published 26 March 2015

Copyright (c) 2015 by authors and Scientific Research Publishing Inc.

This work is licensed under the Creative Commons Attribution International License (CC BY). http://creativecommons.org/licenses/by/4.0/

(c) (i) Open Access

\section{Abstract}

India has witnessed tremendous industrialization in the last five decades. This has led to migration of masses from rural areas towards cities for jobs and businesses. With increase in the population, the demand for residences has also increased which has escalated growth of slum areas and haphazard planning in suburbs. City of Ahmedabad is one such urban metropolis in the state of Gujarat, India. Being the financial capital of Gujarat, population of the city has increased many folds since 1980s. Congested and unsustainable planning and increasing in the emissions from industries and vehicles in certain areas of the city have given birth to many climatic issues. One of these major problems is the Urban Heat Island (UHI) phenomena. This has increased the temperature by four to five degrees and has also severely affected air quality. Satellite based Remote sensing data can provide temperature information of various land use classes. Remote Sensing data along with in-situ surface measurements can help to identify urban heat island intensities and hotspots in the cities. A study on heat island characterization and isotherm mapping was taken up in Ahmedabad City. In the present study, Surface Heat Island (SHI) effect is studied using satellite data along with field measurements. Thermal infrared data from Landsat ETM band-6 have been effectively used for monitoring temperature differences of various land use classes in urban areas. The study aims to identify and study the urban hot spots using the data from LANDSAT-5 and field data collected using IR Gun in various zones of Ahmedabad City. The results of this study

\footnotetext{
${ }^{*}$ Corresponding author.
} 
indicated that the surface temperature near industrial areas and dense urban areas was higher as compared to other suburban areas in the Ahmedabad City.

\title{
Keywords
}

\author{
Surface Temperature, Urban Heat Island (UHI) Phenomena, Hot Spots, Landsat TM, Thermal \\ Infrared, Isotherms, Industrial Area, IR Gun, Geo-Informatics
}

\section{Introduction}

The urban environment—buildings, cities and infrastructure-represents one of the most important contributors to climate change, while at the same time holding the key to a more sustainable way of living. Most urbanization activities are safe, comfortable, economically and functionally efficient. But a few of these activities result in inadvertent environmental and atmospheric alternations. In cities where buildings are concentrated, these activities may result in significant local climate changes. Urbanization typically results in a significant increase in local temperature. The growth of the economy and the process of industrialization and urbanization in the past 40 years have caused many environmental problems such as thermal pollution and heat islands. The solid surface of a town, the thermal properties of street and building materials and surface geometry of built-up areas contribute to further increasing temperatures. Urban environment problems include recent problems like albedo, urban heat island and greenhouse effect.

\section{Urban Heat Island (UHI) Effect}

The urban heat island effect (UHI) is the resulting temperature difference between urban and surrounding rural areas. This phenomenon occurs due to the patterns of urban development which result in the conversion of vegetated, agricultural land areas into urban landscapes dominated by high albedo (i.e. measure of the amount of solar energy that is reflected by a given surface) and impervious surfaces that absorb a high percentage of solar radiation. Urban Heat Islands exist in many large cities and can significantly impact the quality of life in the affected areas. Typically the temperature difference between urban and rural areas ranges from $3^{\circ} \mathrm{C}-5^{\circ} \mathrm{C}$ during the day. However, at night the difference can reach as high as $12^{\circ} \mathrm{C}$ due to the slow radiation of heat from urban surfaces. Solar energy absorbed by roads and rooftops can cause urban surface temperatures to be $10^{\circ} \mathrm{C}-17^{\circ} \mathrm{C}$ higher than the ambient air. "Canyon effects" caused by groups of large buildings with multiple reflecting and absorbing surfaces, can exacerbate the UHI conditions.

Urban heat island effects can raise city air temperatures by $2^{\circ} \mathrm{C}$ to $10^{\circ} \mathrm{C}$ above the surrounding area. Night time temperature differences on calm, clear nights can be as much $22^{\circ} \mathrm{C}$. This is due to the nighttime radiative cooling being limited by buildings (Solecki et al., 2004) [1]. The effect is most intense on calm, clear days in the summer and fall. This is because on clear days, short-wave radiation from the sun travels on a direct path to the earth's surface, and is not obstructed by clouds which can reflect a large proportion of incoming solar radiation. Furthermore, while the UHI occurs year-round its occurrence during the summer is of primary concern due to the impacts related to increased electricity and air conditioning use, as well as the increased frequency of heatrelated illness and mortality during high summer temperatures (Rosenzweig et al., 2006) [2]. The intensity of the UHI also tends to vary depending on the size of cities. Generally speaking, the intensity of the UHI increases as the size of a city increases, due to the larger size of the built area (Rinner \& Hussain, 2011) [3]. The UHI leads to elevated temperature, higher energy consumption, increased pollution, and related health risks. Elevated temperatures result in increased summertime peak energy demand adding pressure to the electricity grid.

With the recent economic and industrial development and GDP growth rate reaching about $7.4 \%$ in India, it has come out as major energy consumer among the developing countries globally. According to the Government of India, Ministry of Statistics and Programme Implementation, the per capita energy consumption has increased almost four-folds in four decades during 1970-2010 year. But in a period of 1980-2010 during last three decades, India's annual energy consumption has increased five-folds (4-quadrillion Btu to 22-quadrillion Btu). This owes to the improved urban living standards and advanced means of energy consumption from households to industrial sector. 
Buildings in India generally are responsible for at least 30\% - 40\% of energy use and this demand is growing annually at $11 \%-12 \%$, which is almost twice the average electricity growth in the economy which is $5 \%-6 \%$ annually. GRIHA manual cites that there is an increased demand of about 5.4 billion units of electricity annually for residential and commercial buildings. In a typical building, approximately $80 \%$ - 90\% of the energy is consumed for heating, cooling, lightning and other appliances. The other $10 \%-20 \%$ is utilized during construction and material manufacturing. Apart from being a leading energy consumer in the infrastructure sector, buildings are also prime generators of Green House Gases (GHG), thus posing a threat to the environment. Globally, the urban areas contribute $70 \%$ while the housing construction and estate development contribute $40 \%$ to the GHG emissions. Buildings contribute approximately $50 \%$ of the world's air pollution, $42 \%$ of GHG emissions, 50\% of water pollution, $48 \%$ of solid waste and $50 \%$ of CFCs (chlorofluorocarbons) to the environment. This is an alarming issue which needs to be addressed by developing energy efficient building design which would facilitate minimization of energy consumption and will spur sustainable growth. On a macro-view, buildings in India are seldom designed to reduce the embodied and operational energy. Trends are rising on reducing the water needs and technologies to recycle used water for secondary usage are getting implemented. Still, the energy issue remains unaddressed. Energy efficient building design in India on a macro-scale can prove to be the most promising option since the building sector has the largest potential for reducing GHG emissions significantly.

\section{Literature survey}

\subsection{World Scenario}

Zong-Ci et al., 2013 [4] stated that in 2009 more than 50\% of the world's population was living in urban area and it was expected that by 2050 this figure would reach to $70 \%$ and this urbanization is the main cause for urban heat island effect. He carried out a study of UHI (Urban Heat Island) for china and ultimately stated that UHI contributed to $0.2-0.33$ of the total warming in China in the last 50 years. According to Streutker, 2002 [5], the main reasons for UHI are differences in the thermal properties of the radiating surfaces and a decreased rate of evapo-transpiration in the urban environment. (Hensen et al., 2002) [6] in their paper described the importance of building energy performance in the contemporary construction industry. It discussed the present status of the penetration of the simulation softwares among the planners and property developers. Furthermore, it introduced the International Building Performance Simulation Association (IBPSA) and its objectives. The broad areas covered by IBPSA included building physics, energy supply systems, HVAC, building services, human factors. Also, the stage of application and level of resolution of the above mentioned topics were been discussed.

Roberto Fabrizi, 2010, [7] studied, the trend of the Urban Heat Island (UHI) of Rome is analyzed by both ground-based weather stations and a satellite-based infrared sensor. First, we have developed a suitable algorithm employing satellite brightness temperatures for the estimation of the air temperature belonging to the layer of air closest to the surface. UHI spatial characteristics have been assessed using air temperatures measured by both weather stations and brightness temperature maps from the Advanced along Track Scanning Radiometer (AATSR) on board ENVISAT polar-orbiting satellite. In total, 634 daytime and nighttime scenes taken between 2003 and 2006 have been processed. Analysis of the Canopy Layer Heat Island (CLHI) during summer months reveals a mean growth in magnitude of 3 - $4 \mathrm{~K}$ during nighttime and a negative or almost zero CLHI intensity during daytime, confirmed by the weather stations.

Growth of the surface temperature urban heat island (UHI) of Houston, TX is determined by comparing two sets of heat island measurements taken 12 years apart. Individual heat island characteristics are calculated from radiative temperature maps obtained using the split-window infrared channels of the Advanced Very High Resolution Radiometer (AVHRR) on board National Oceanic and Atmospheric Administration polar-orbiting satellites (David R. Streutker, 2003) [8].

The UHI describes quantitatively the increased temperature of either the urban surface or the urban atmosphere compared to its rural surroundings. The temporal and spatial characteristics of the UHI vary with changes in local urban form and function. Local meteorological conditions, geography (topography, presence of water bodies such as lakes or rivers, soil types, etc.) also affect the magnitude of an UHI. Also, population, as a surrogate measure of the density of urban living, was originally linked to UHI intensity (Oke, T.R., 1973) [9]. There are three types of UHI (Voogt, J.A) [10]:

1) Canopy Layer Heat Island (CLHI); 2) Boundary Layer Heat Island (BLHI); 3) Surface Heat Island (SHI).

The CLHI and the BLHI refer to a warming of the urban atmosphere whereas the SHI refers to a warming of 
the surface. The urban canopy layer is the layer of air closest to the surface in cities, extending upwards to approximately the mean building height. Above the canopy layer lays the urban boundary layer, which may be 1 $\mathrm{km}$ or more in thickness at daytime, shrinking to hundreds of meters or less at night.

\subsection{Indian Scenario}

In India, Patki and Alange, 2006 [11] focused their study on finding out whether change in various land cover in Pune contributes to the change in land surface temperature over a period from 1999 to 2006 and as an outcome it was found that the built up area was increased $32.68 \%$ which lead to a sharp decline of $10 \%$ area in agriculture, 21.91\% area in barren land in mostly attributing to intense urbanization process and Vegetation had been decreased by $10 \%$. As a result, there had been a $1^{\circ} \mathrm{C}$ to $4^{\circ} \mathrm{C}$ rise in surface temperature in Pune since 1999 to 2006. Mohan et al., 2009 [12] in their research divided the city of New Delhi, India in to 30 stations out of which 3 were weather stations and remaining 27 were micrometeorological stations to study urban heat island (UHI) effect. The stations were categorized in dense, medium and less dense urban areas, industrial areas, green areas, open areas, riverside areas, etc. After the complete survey, it was observed that the top 3 UHI's were located in commercial areas and then in decreasing order from residential urban areas, river bedsides and lowest UHI's were located at green and forest areas.

According to Vidal and Pathak 2013 [13], the temperature was expected to rise to a sizzling $46^{\circ} \mathrm{C}$ in the mega-city of India, which are the home to an estimated 18 million people. A primary data carried by Delhi-based Energy and Resources Institute (TERI) showed that the temperatures in the 2 mega-cities Mumbai and Delhi had risen $20^{\circ} \mathrm{C}-30^{\circ} \mathrm{C}$ in only 15 years. The study, based on NASA satellite readings, also showed the cities to be $50^{\circ} \mathrm{C}-70^{\circ} \mathrm{C}$ warmer than in the surrounding rural areas on summer nights. A case study was undertaken to assess and compare UHI and Hotspots based on in-situ measurements and Remote Sensing observations in the megacity of Delhi. Urban heat island effects were found to be more dominant in areas of dense built up infrastructure and at commercial centres. The UHI intensity was observed to be higher in magnitude both during afternoon hours and midnight hours. The three high ranking UHI locations in the Delhi City were within commercial and densely populated areas (ManjuMohan et al., 2012) [12]. The results of this field campaign when compared with MODIS-Terra data of land surface temperature revealed that UHI hotspots were comparable only with during night time.

Urban Heat Island (UHI), a measure of the near surface air temperature contrast between urbanized and adjoining rural areas, is the most pronounced effect of urbanization. The definition of "urban" varies in different contexts, which makes it difficult for direct comparison between cities in different regions. Local climate zone (LCZ) classification based method was adopted in Kochi in Southern India to study its UHI. Maximum intensity was seen in Compact Midrise zones which cover the central part of the city. Most intense cooling was observed in openset and sparsely built regions in all seasons. Standard zone properties alone were inadequate to explain variation of UHI intensity of same classes with different surface area and diverse adjacent zones (George Thomas, Sherin A.P, Shareekul Ansar, E.J. Zachariah, 2014) [14].

\section{Objectives}

This research study was undertaken at Bhaskaracharya Institute for Space Applications and Geo-informatics (BISAG), with following major objectives:

- To study the urban heat island characterization using Landat TM thermal data and field data collected using IR Gun in various zones of Ahmedabad City.

- Generation of Isotherm maps for various zones of the Ahmedabad City.

- Study of urban land cover type and surface temperature and its impact on Urban Heat island phenomena

\section{Study Area}

City of Ahmedabad is one such urban metropolis in the state of Gujarat, India. Being the financial capital of Gujarat, population of the city has increased many folds since 1980s. Congested and unsustainable planning and increasing in the emissions from industries and vehicles in certain areas of the city has given birth to many climatic issues. One of the major problems is the Urban Heat Island phenomena (UHI) in the large cities. The location map of the study area is given in Figure 1. 


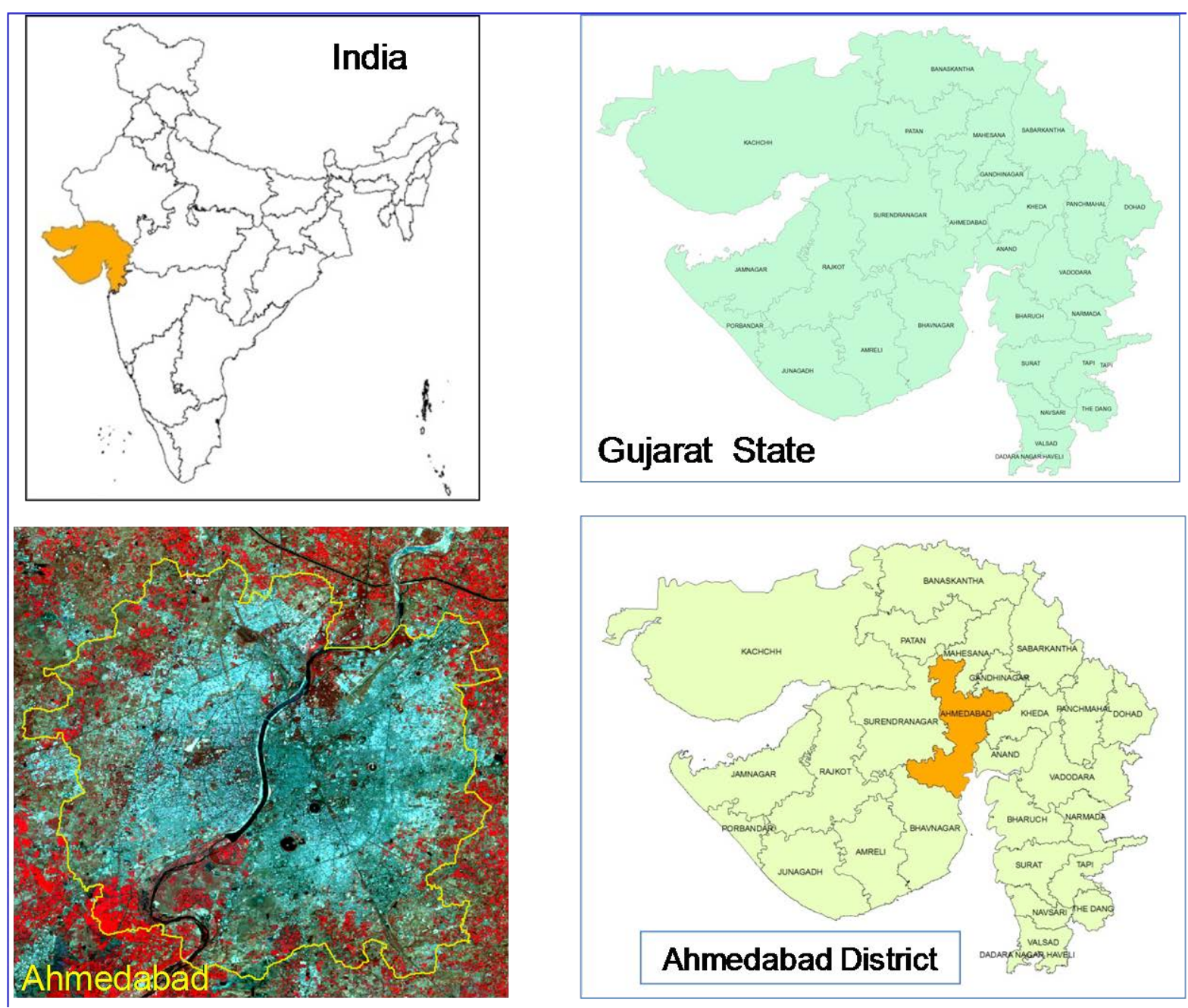

Figure 1. Location map of study area in Gujarat State.

\section{Methodology}

The present research is focused on studying the urban heat island phenomena for the Ahmedabad City; identify the factors responsible for increasing this effect; studying the role of building materials in capturing the solar radiation and increasing the local temperature.

\subsection{Data Used}

Landsat TM data covering Ahmedabad City was downloaded from the NASA website. Landsat TM data of winter (January-2013) and summer (April-2013) seasons was analysed for studying the Urban Heat Island phenomena (UHI).

\subsection{Field Data Collection}

The research methodology consists of thermal data analysis of selected fifty points evenly distributed in various zones of Ahmedabad City. The field data has been collected using the Infrared Gun for different time periods morning (10:00 to 11:00 hrs), afternoon (14:00 to 15:00 hrs) and evening (18:00 to 19:00 hrs). The survey was conducted twice, first, during 21st January, 2014 and then during 11th April, 2014. The Ahmedabad City was divided into six zones as per the administrative boundaries of the city. The zones selected were North zone, South zone, East zone, Central zone, West zone, and new West zone. In each zone, on an average six various 
building surfaces were selected depending on building orientation, surface heat gain capacity. The surface temperature of each selected building was measured using the IR-Gun (Figure 2).

For collecting temperature data various sites in each administrative zone of Ahmedabad City were selected based on various parameters like urban development, open spaces, industrial development and presence of parks and gardens in the area. These sites were randomly selected based on the zonation of the Ahmedabad City. The temperature data collected for south zone of Ahmedabad City during morning, afternoon and evening hours in the month of January and April-2014 are given in Table 1 and Table 2. To study the solar radiation capture capacity of different materials and their probable effect on urban heat island effect, a 3-day consecutive survey
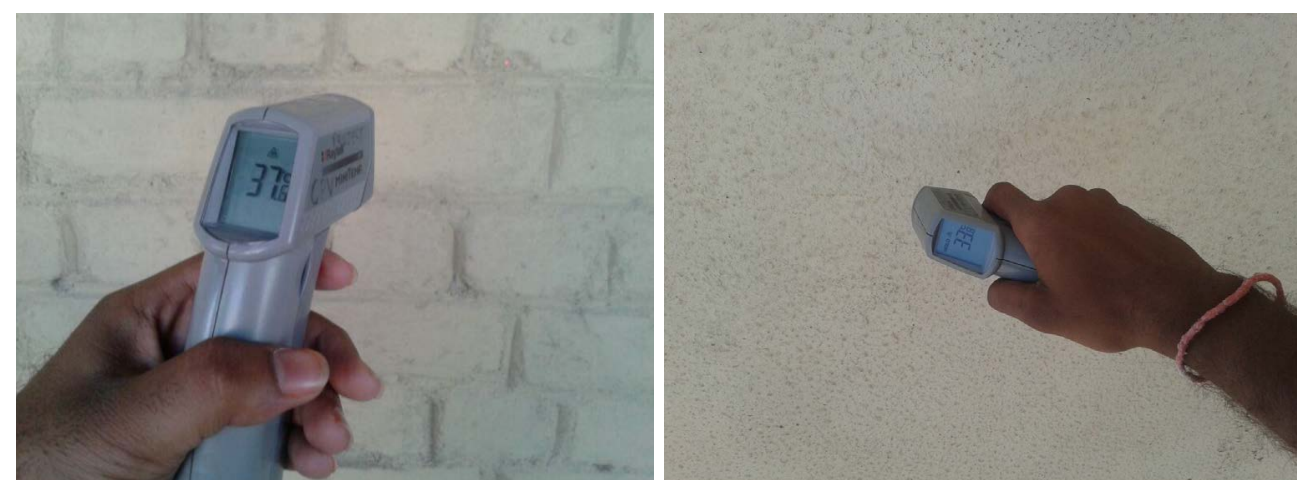

Figure 2. Field photos of temperature data collection using IR Gun.

Table 1. Field temperature data collected during 21-Jan-2014 in south zone of Ahmedabad City.

\begin{tabular}{cccccc}
\hline Stations & $\begin{array}{c}\text { Morning } \\
(10: 00-11: 00)\end{array}$ & $\begin{array}{c}\text { Afternoon } \\
(14: 30-15: 30)\end{array}$ & $\begin{array}{c}\text { Evening } \\
(18: 30-19: 30)\end{array}$ & Latitude & Longitude \\
\hline Maninagar & 33.2 & 36.8 & 35.4 & 22.9980 & 72.6033 \\
Narol & 32.5 & 37.0 & 34.3 & 22.9813 & 72.6102 \\
Khokhra & 33.1 & 36.7 & 35.7 & 22.9957 & 72.6180 \\
Kankariya & 31.4 & 36.5 & 34.9 & 23.0094 & 72.5988 \\
Isanpur & 32.6 & 37.3 & 34.8 & 22.9700 & 72.5944 \\
Danilimda & 32.9 & 36.4 & 33.7 & 22.9962 & 72.5840 \\
Townhall & 28.2 & 30.4 & 29.8 & 23.0224 & 72.5652 \\
\hline
\end{tabular}

Table 2. Field temperature data collected during 11-April-2014 in south zone of Ahmedabad City.

\begin{tabular}{cccccc}
\hline Stations & $\begin{array}{c}\text { Morning } \\
(10: 00-11: 00)\end{array}$ & $\begin{array}{c}\text { Afternoon } \\
(14: 30-15: 30)\end{array}$ & $\begin{array}{c}\text { Evening } \\
(18: 30-19: 30)\end{array}$ & Latitude & Longitude \\
\hline Maninagar & 43.1 & 50.6 & 44.6 & 22.998 & 72.6033 \\
Narol & 42 & 47.7 & 44.1 & 22.98128 & 72.61021 \\
Khokhra & 42.6 & 46.8 & 43.8 & 22.99576 & 72.61807 \\
Kankariya & 41.8 & 46.7 & 43.6 & 23.00944 & 72.59885 \\
Isanpur & 42.3 & 46.9 & 44.1 & 22.97006 & 72.59442 \\
Danilimda & 43.2 & 47.3 & 45.2 & 22.99625 & 72.58407 \\
Townhall & 42.8 & 46.5 & 44.9 & 23.02246 & 72.56523 \\
\hline
\end{tabular}


was carried out. In this survey five different materials i.e. Grass, Concrete blocks, Bricks, Soil surface, and a brick wall with $3 \mathrm{~mm}$ plastered surface was selected The surface temperature of each material was measured and tabulated (Table 3) for generation of isotherms.

\subsection{Satellite Data Analysis}

Urban heat island studies are generally conducted in one of two ways: measuring the UHI in air temperature through the use of automobile transects and weather station networks, and measuring the UHI in surface (or skin) temperature through the use of airborne or satellite remote sensing. In situ data have the advantage of a high temporal resolution and a long data record, but have poor spatial resolution. Conversely, remotely sensed data has higher spatial distribution but low temporal resolution and a shorter data record. In recent years, the field of remote sensing has lent itself well to the study of UHI's. Roth, Oke, and Emery (1989) [15] and Gallo and Tarpley (1996) [16] used remote sensing techniques to compare the UHI effect to vegetation index. Landsat TM data covering Ahmedabad City area was analysed using ENVI 4.5 image processing software and this broadly consists of following major steps:

1) multi-date data preparation and geo-referencing,

2) Ahmedabad City Administrative boundary superimposing,

3) superimposing GPS locations of field data collection points on the registered landsat TM digital data,

4) generation of temperature values from the Landsat TM thermal data,

5) generation of Iso-thermal maps of the six administrative zones of the city using Quantum GIS software-1.8.

The geo-referenced image covering Ahmedabad Muncipal Corporation area is given in Figure 3. The Ahmedabad Muncipal Corporation boundary and locations of field data collection using IR Gun were also superimposed on georeferenced satellite image (Figure 4).

\subsection{Satellite Data Analysis of Two Seasons}

The LANDSAT-5 TM images have been analysed using ENVI software version 4.5. The images of all the seven bands were stacked using the layer-stacking tool to generate a layer-stacked image having the attributes of all the bands. The Landsat TM data of 14-Jan-2013 and 26-Apr-2013 used in this study is given in Figure 5.

The Region of Interest (ROI) tool has been used to select the ROIs across the city of size $10 \times 10$ pixels. The DN values of these ROIs have been used to derive the surface temperature using with Landsat-Temperature Model. This model directly converts to spectral radiance to temperature. It is a three steps process:

\section{Step 1: Conversion of the Digital Number (DN) to Spectral Radiance (L)}

$$
\mathrm{L}=\mathrm{L}_{\min }+\left(\mathrm{L}_{\max }-\mathrm{L}_{\min }\right) \times \frac{\mathrm{DN}}{255}
$$

where,

$\mathrm{L}=$ Spectral Radiance,

$\mathrm{L}_{\min }=1.238$ (Spectral radiance of DN value 1).

Table 3. Surface temperature data collection for different materials.

\begin{tabular}{cccccc}
\hline \multirow{2}{*}{ Material } & \multicolumn{5}{c}{ Date: 06-May-2014 } \\
\cline { 2 - 5 } & $09: 00$ & $11: 00$ & $13: 00$ & $15: 00$ & $17: 00$ \\
\hline Grass & 35.9 & 39.7 & 42.0 & 43.9 & 41.3 \\
Concrete Block & 41.9 & 57.1 & 58.3 & 63.1 & 59.6 \\
Brick & 44.4 & 50.9 & 53.9 & 58.9 & 57.8 \\
Soil & 44.9 & 60.3 & 62.4 & 64.7 & 61.2 \\
Wall (3 mm, Plastered) & 38.7 & 44.3 & 49.5 & 51.9 & 54.0 \\
\hline
\end{tabular}

Temperature values in ${ }^{\circ} \mathrm{C}$. 


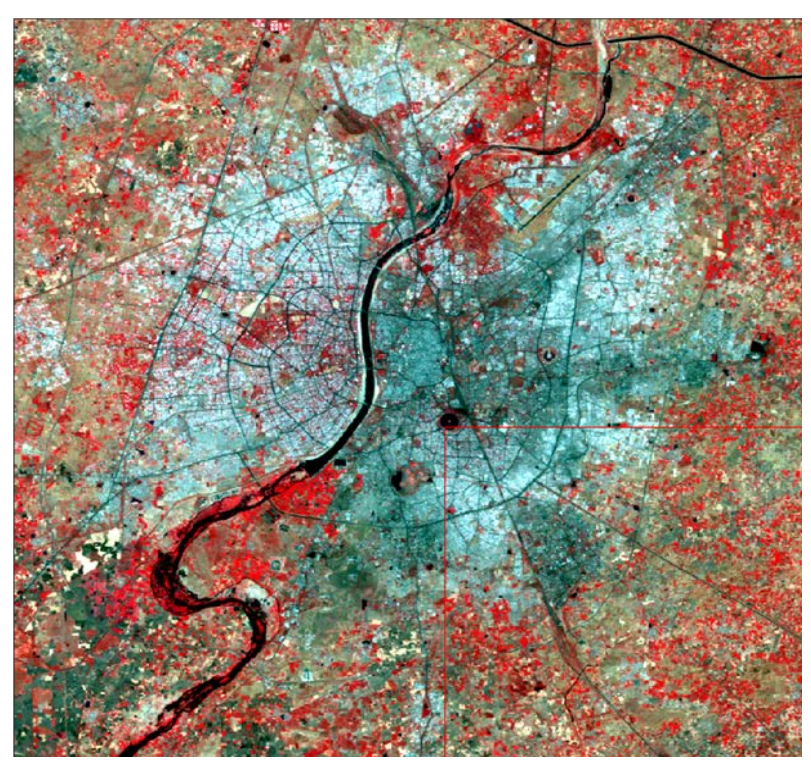

Figure 3. Geo-referenced image covering Ahmedabad City.

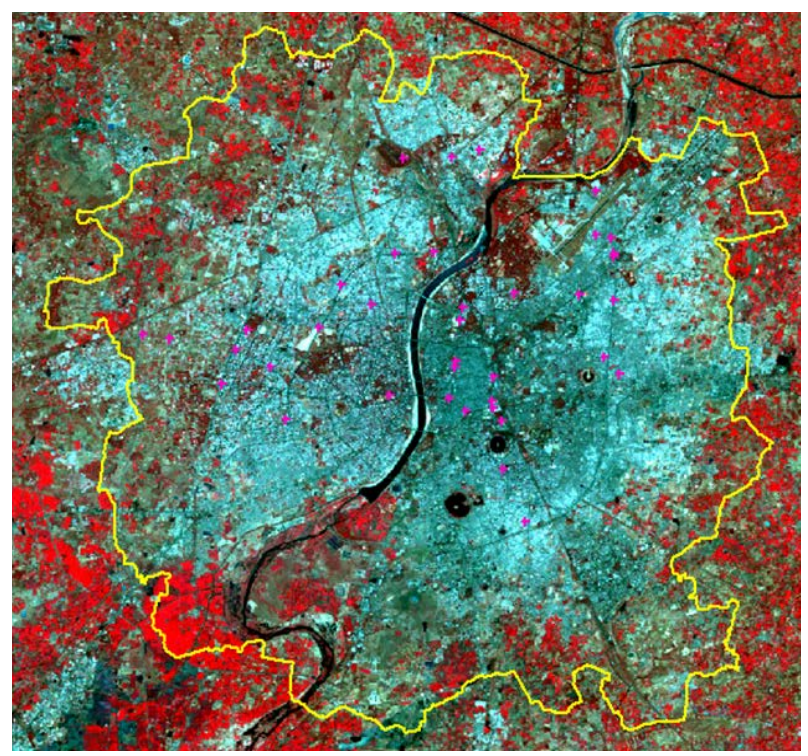

Figure 4. Geo-referenced image with Ahmedabad City boundary and locations of data collection using IR Gun.
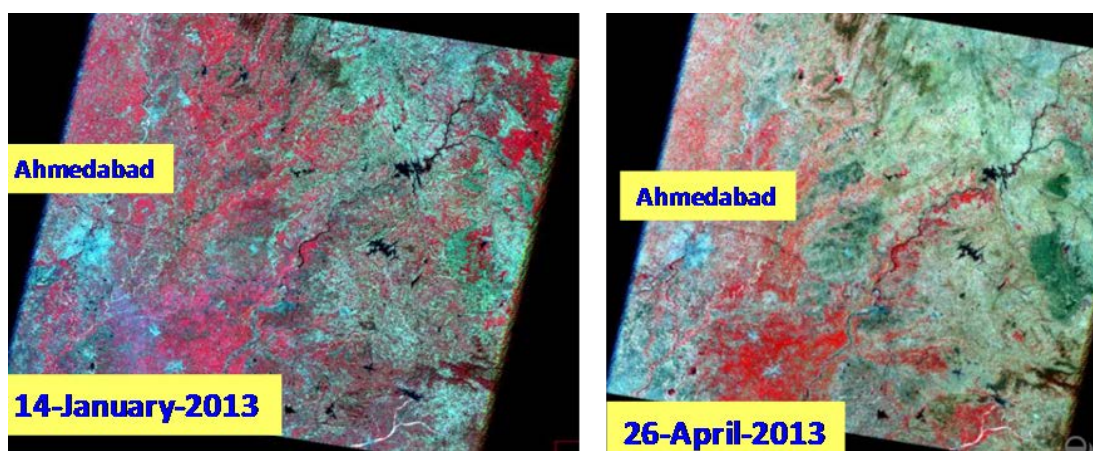

Figure 5. LANDSAT-5 TM images covering Ahmedabad City. 
DN $=$ Digital Number.

$\mathrm{L}_{\max }=15,600$ (Spectral radiance of DN value 255).

Step 2: Conversion of Spectral Radiance to Temperature in Kelvin

$$
\mathrm{Tb}=\frac{\mathrm{K} 2}{\left(\ln \left(\frac{\mathrm{K} 1}{\mathrm{~L}}\right)+1\right)}
$$

where,

K1= Calibration Constant 1 (Landset-5 TM Band 6 value $607.76 \mathrm{~W} / \mathrm{cm}^{2} / \mathrm{sr} / \mu \mathrm{m}$ ).

$\mathrm{K} 2$ = Calibration Constant 2 (Landset-5 TM Band 6 value $1260.56 \mathrm{~W} / \mathrm{cm}^{2} / \mathrm{sr} / \mu \mathrm{m}$ ).

$\mathrm{Tb}=$ Surface Temperature.

Step 3: Conversion of Kelvin to Celsius

$$
\mathrm{T}_{\mathrm{B}}=\mathrm{T}_{\mathrm{B}}-273
$$

\subsection{Generation of Isotherms for Ahmedabad City}

The generation of isotherms is done using Quantum GIS software version 1.8.0. The temperature data in the form of delimited text is used for the generation of a shape file. Further the shape file is used for generation of the isotherms using the Polygonize (Raster to Vector) function in the Raster menu. Table 4 displays the temperature ranges selected for the isotherm generation.

Based on these temperature ranges isotherm maps for Ahmedabad City were generated from the Landsat TM data of January and April using Quantum GIS software. The steps followed to generate isotherm map for the city are given below:

- Identification of region of interest (ROI) from the layer stacked image,

- Calculation of surface temperature for selected ROI using image processing software ENVI version 4.5,

- Using the ROIs in the stacked image, isotherms are generated using Q-GIS software 1.8,

- Classification of the contours in three different classes viz.

1) Class-1: $\left.18^{\circ} \mathrm{C}-28^{\circ} \mathrm{C}, 2\right)$ Class-2: $28^{\circ} \mathrm{C}-36^{\circ} \mathrm{C}$, 3) Class-3: $\geq 36^{\circ} \mathrm{C}$.

\subsubsection{Isotherms Based on Landsat TM Data}

The isotherms for various zones of Ahmedabad City were generated using the Landsat TM data of January and April using Quantum GIS software. The isotherms of one of the zones are given in Figure 6. The isotherms are divided into several temperature zones for further analysis. These iso-therm maps were used to identify major urban hot spots across the Ahmedabad City.

\subsubsection{Isotherms Based on Field Data}

The field data was collected uing IR Gun on 14-January and 26-April-2014 during morning (1000 - 1100 hrs), afternoon (1400 - $1500 \mathrm{hrs})$ and evening (1800 - $1900 \mathrm{hrs})$. This data was collected at different selected locations in different zones of Ahmedabad City. From this data isotherms were generated using Quantum GIS software (Figure 7). From the analysis of isotherms of various zones, it was inferred that areas exposed to medium to dense vehicular traffic and having dense buildings display higher temperature range. These regions include the Gujarat Industrial Development Corporation (GIDC) Naroda, Central and Old city and the New West area including Satellite, Sola and Sarkhej.

Table 4. Temperature ranges selected for the isotherm generation.

\begin{tabular}{cc}
\hline Class no. & Temperature Range $\left[{ }^{\circ} \mathrm{C}\right]$ \\
1 & $18-28$ \\
2 & $28-36$ \\
3 & $\geq 37$ \\
\hline
\end{tabular}



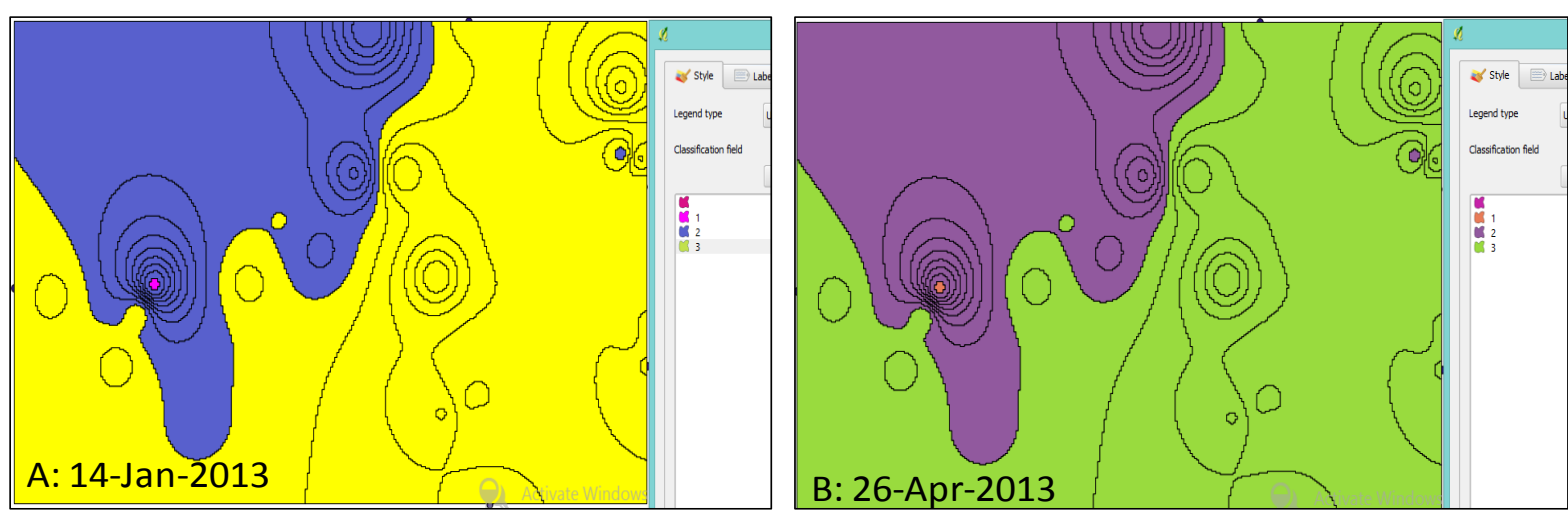

Figure 6. Temperature isotherms based on LANDSAT-5 TM data of January and April covering part of Ahmedabad City.

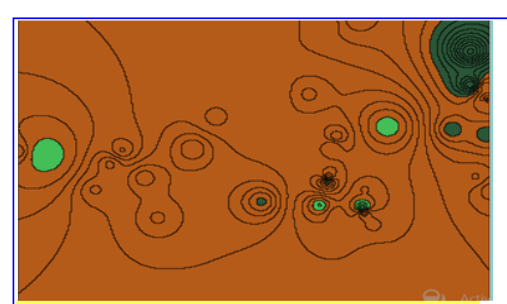

14-Jan-14: Time: 1000-1100 hrs

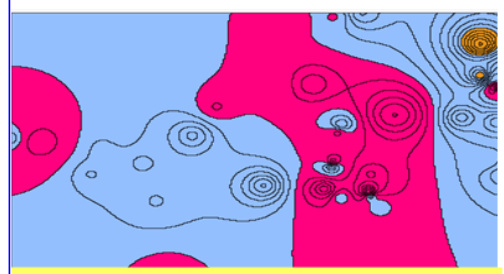

14-Jan-14: Time: 1400-1500 hrs

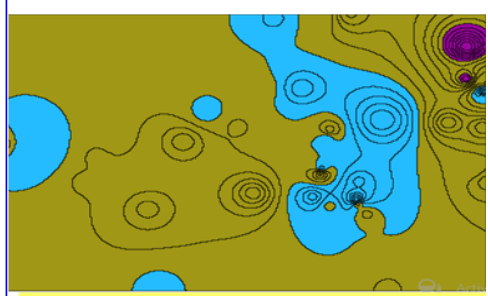

14-Jan-14: Time: 1800-1900 hrs

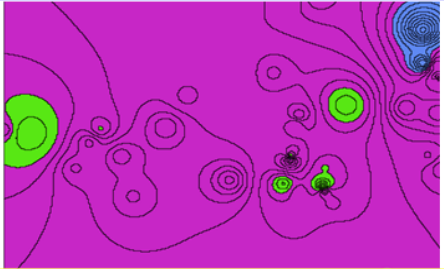

26-Apr-14: Time:1000-1100 hrs

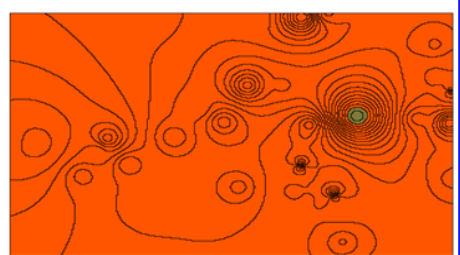

26-Apr-14: Time: 1400-1500 hrs

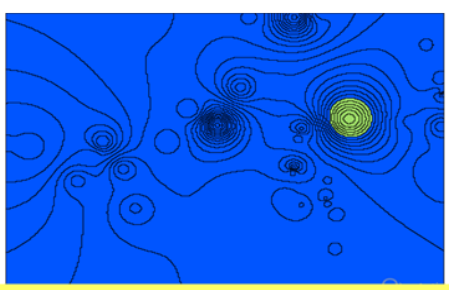

26-Apr-14: Time: 1800-1900 hrs

Figure 7. Temperature isotherms based on field data of January and April during different time period.

\section{Conclusions}

The present study on urban heat island characterization using Landat TM thermal data and field data collected using IR Gun was carried out in Ahmedabad City, Gujarat State, India. Landsat TM data covering Ahmedabad City of winter (January-2013) and summer (April-2013) seasons was downloaded from the NASA website. For collecting field data using IR Gun, Amedabad city city was divided into six zones and field data was collected at different locations in each zone. The satellite thermal data and the surface temperature data collected at various locations have been used to generate isothermal map for the entire Ahmedabad City.

The major conclusions of the study are as follows:

- The isotherms generated using Landsat TM data were used to divide the Ahmedabad City into regions having surface temperature in three ranges $-18^{\circ} \mathrm{C}-28^{\circ} \mathrm{C} ; 28^{\circ} \mathrm{C}-36^{\circ} \mathrm{C}$ and more than $36^{\circ} \mathrm{C}$. 
- The UHI effect has been found to be higher in the Gujarat Industrial Development Corporation (GIDC) Naroda, the old densely populated Ahmedabad City and the newly developing new west zone which includes Bopal, Sarkhej and Thaltej. These areas experienced temperature in the range of $35^{\circ} \mathrm{C}-46^{\circ} \mathrm{C}$ during the major time of the day.

- Analysis of LANDSAT-5 TM for the month of January and April, 2013 indicated that the urban heat island intensity in Ahmedabad City was higher during summer Season (April) as compared winter season (January).

- The temperature data collected using IR Gun at various locations in Ahmedabad City during morning, afternoon and evening times indicated that:

1) UHI effect was higher during summer season as compared to winter season.

2) UHI effect was higher during afternoon period as compared to morning and even it continued till evening time at all the locations in Ahmedabad City.

\section{Acknowledgements}

The authors express their sincere thanks to Shri T. P. Singh, Director, Bhaskarcharya Institute for Space Applications and Geo-informatics (BISAG), Department of Science \& Technology, Government of Gujarat, Gandhinagar for his encouragement to conduct this study.

\section{References}

[1] Solecki, W., Rosenzweig, R., Pope, G., Chopping, M., Goldberg, R. and Polissar, A. (2004) Urban Heat Island and Climate Change: An Assessment of Interacting and Possible Adaptations in the Camden, New Jersey Region.

[2] Rosenzweig, C., Solecki, W. and Slosberg, R. (2006) Mitigating New York City’s Heat Island with Urban Forestry, Living Roofs, and Light Surfaces. New York State Energy Research and Development Authority, Albany.

[3] Rinner, C. and Hussain, M. (2011) Toronto's Urban Heat Island-Exploring the Relationship between Land Use and Surface Temperature. Remote Sensing, 3, 1251-1265. http://dx.doi.org/10.3390/rs3061251

[4] Zhao, Z.C., Luo, Y. and Huang, J.B. (2012) Are There Impacts of Urban Heat Island on Future Climate Change? Advances in Climate Change Research, 4, 1-4.

[5] Streutker, D. (2002) A Remote Sensing Study of the Urban Heat Island of Houston, Texas. Journal of Remote Sensing, 23, 2595-2608. http://dx.doi.org/10.3390/rs3061251

[6] Hensen, J.L.M., Lamberts, R. and Negrao, C.O.R. (2002) A View of Energy and Building Performance Simulation at the Start of the Third Millennium. Energy and Buildings, 34, 853-855. http://dx.doi.org/10.1016/S0378-7788(02)00063-4

[7] Fabrizi, R., Bonafoni, S. and Biondi, R. (2010) Satellite and Ground-Based Sensors for the Urban Heat Island Analysis in the City of Rome. Remote Sensing, 2, 1400-1415. http://dx.doi.org/10.3390/rs2051400

[8] Streutker, D.R. (2003) Satellite-Measured Growth of the Urban Heat Island of Houston, Texas. Remote Sensing of Environment, 85, 282-289. http://dx.doi.org/10.1016/S0034-4257(03)00007-5

[9] Oke, T.R. (1973) City Size and the Urban Heat Island. Atmospheric Environment, 7, 769-779. http://dx.doi.org/10.1016/0004-6981(73)90140-6

[10] Voogt, J.A. (2004) Urban Heat Island: Hotter Cities. Action Bioscience, North Port. http://www.actionbioscience.org/environment/voogt.html

[11] Nesarikar-Patki1, P. and Raykar-Alange, P. (2012) Study of Influence of Land Cover on Urban Heat Islands in Pune Using Remote. IOSR Journal of Mechanical and Civil Engineering (IOSR-JMCE), 3, 39-43.

[12] Mohan, M., Kikegawa, Y., Gurjar, B., Bhati, S., Kandya, A. and Ogawa, K. (2012) Urban Heat Island Assessment for a Tropical Urban Airshed in India. Atmospheric and Climate Sciences, 2, 127-138. http://dx.doi.org/10.4236/acs.2012.22014

[13] Stewart, I.D. and Oke, T.R. (2012) Local Climate Zones for Urban Temperature Studies. Bulletin of the American Meteorological Society, 93, 1879-1900. http://dx.doi.org/10.1175/BAMS-D-11-00019.1

[14] Thomas, G., Sherin, A.P., Ansar, S. and Zachariah, E.J. (2014) Analysis of Urban Heat Island in Kochi, India, Using a Modified Local Climate Zone Classification. Procedia Environmental Sciences, 21, 3-13.

[15] Roth, M., Oke, T.R. and Emery, W.J. (1989) Satellite-Derived Urban Heat Islands from Three Coastal Cities and the Utilization of Such Data in Urban Climatology. International Journal of Remote Sensing, 10, 1699-1720. http://dx.doi.org/10.1080/01431168908904002 
[16] Gallo, K.P. and Tarpley, J.D. (1996) The Comparison of Vegetation Index and Surface Temperature Composites for Urban Heat-Island Analysis. International Journal of Remote Sensing, 17, 3071-3076.

http://dx.doi.org/10.1080/01431169608949128 